\title{
Diagnostic and prognostic significance of glypican 5 and glypican 6 gene expression levels in gastric adenocarcinoma
}

\author{
MELIKE DINCCELIK-ASLAN ${ }^{1}$, GUVEM GUMUS-AKAY ${ }^{2}$, \\ ATILLA HALIL ELHAN ${ }^{3}$, EKREM UNAL $^{4}$ and AJLAN TUKUN ${ }^{5}$
}

\begin{abstract}
${ }^{1}$ Biotechnology Institute, Ankara University, Golbasi, Ankara 06830; ${ }^{2}$ Brain Research Centre, Ankara University, Mamak, Ankara 06900; ${ }^{3}$ Department of Biostatistics, Faculty of Medicine, Ankara University, Sihhiye, Ankara 06100; ${ }^{4}$ Department of Surgical Oncology, Research and Training Hospital, Faculty of Medicine, Ankara University, Cebeci, Ankara 06580; ${ }^{5}$ Department of Medical Genetics, Faculty of Medicine, Ankara University, Sihhiye, Ankara 06100, Turkey
\end{abstract}

Received May 16, 2014; Accepted December 9, 2014

DOI: $10.3892 / \mathrm{mco} .2015 .486$

\begin{abstract}
Gastric cancer is one of the most common malignancies worldwide and the second most common cause of cancer-related mortality. Previous studies revealed several genetic alterations specific to gastric cancer. In this study, we aimed to investigate the diagnostic and prognostic significance of the expression levels of the glypican 5 and glypican 6 genes (GPC5 and GPC6, respectively) in gastric cancer. For this purpose, GPC5 and GPC6 expression was quantitatively determined by quantitative polymerase chain reaction method in normal gastric mucosa and intestinal type gastric adenocarcinoma samples from 35 patients. The expression levels of GPC5 and GPC6 were compared between normal and tumor tissues. Additionally, the association of the expression levels in tumor tissues with several clinicopathological parameters was evaluated. Although GPC5 was not expressed in any of the samples, the expression of GPC6, which was detected in both groups, was found to be significantly higher in tumor tissues compared to that in normal samples $(\mathrm{P}=0.039)$. However, there was no statistically significant association between GPC6 expression and any of the clinicopathological parameters investigated $(\mathrm{P}>0.05)$. Our findings suggested that an increase in GPC6 expression levels may be implicated in gastric cancer development, but not in cancer progression.
\end{abstract}

\section{Introduction}

Gastric cancer is the second cause of cancer-related mortality worldwide (1). Similar to all other solid tumors, genetic and environmental factors play an important role in gastric cancer development and progression (2). Previous studies have clearly

Correspondence to: Professor Ajlan Tukun, Department of Medical Genetics, Faculty of Medicine, Ankara University, Adnan Saygun Street, Sihhiye, Ankara 06100, Turkey

E-mail: tukun@medicine.ankara.edu.tr

Key words: gastric cancer, glypican 5, glypican 6, expression, quantitative polymerase chain reaction demonstrated that multiple genetic alterations are responsible for the development and progression of gastric cancer $(2,3)$. Genomic amplification is one of the most common types of genetic abnormalities encountered in gastric cancer and frequently leads to the overexpression of genes that may affect cellular behavior. Therefore, the identification of the genes residing at the genomic amplification regions may help researchers elucidate the details of the tumorigenic processes in gastric cancer and identify diagnostic and/or prognostic markers, which may also serve as novel target molecules for the treatment of this disease $(4,5)$.

In our previous study, among the DNA copy number changes detected with the high-resolution-comparative genomic hybridization (HR-CGH) method, 13q amplification with a minimally overlapping region (MOR) 13q21-q32 was found to be significantly associated with lymph node metastasis in gastric adenocarcinoma. When the genes at the MOR were examined, glypican 5 (GPC5) and glypican 6 (GPC6) were considered to be candidate genes that may be involved in gastric carcinogenesis (6).

GPC5 and GPC6 are members of the glypican gene family, which has 6 members in the human genome, namely GPC1-GPC6. All these genes encode different glypicans belonging to the family of heparan sulfate proteoglycans (HSPGs) found attached to the cell membranes and located in the extracellular matrix. Glypicans are composed of a core protein molecule and $\geq 1$ glycosaminoglycan chains that are covalently bound to specific sites on this core. HSPGs are structural components of tissue organization and have important biological functions in cellular proliferation, adhesion, migration and differentiation $(7,8)$, all of which depend on interactions with extracellular and/or cytoplasmic ligands (9).

Glypicans are predominantly expressed during development and it has been demonstrated that expression levels vary in a spatiotemporal manner, suggesting that glypicans are involved in morphogenesis $(10,11)$. In addition, it has been clearly established that glypicans are required for the optimal activity of heparin-binding factors, including fibroblast growth factors (FGFs) and Wnt $(12,13)$. Due to their negatively charged sulfate groups on HS chains, glypicans act as co-receptors that facilitate the formation of ligand-receptor complexes and 
effectively reduce the ligand concentration that is required for function. Therefore, glypicans play an important role in growth factor-mediated signal transduction and it is not surprising that they are expressed in tumoral microenvironments (14). In addition, since glypicans mediate the formation of cell-cell and cell-extracellular matrix adhesions, they exert pro- as well as anti-tumorigenic effects (15-20).

Glypican members have been shown to be associated with the tumorigenic process, frequently via affecting growth factor signaling and cell proliferation. For example, increased GPC1 expression in human gliomas and glioma-derived cell lines have been reported and it has been suggested that GPC1 acts by enhancing FGF basic signaling and mitogenesis (21). Similarly, GPCl overexpression has been demonstrated in pancreatic cancer cells and it has been suggested that GPC1 plays an essential role in the response of pancreatic cancer cells to certain mitogenic stimuli, such as FGF and heparin-binding epidermal growth factor (EGF)-like growth factor (22). The role of GPC3 in tumorigenesis is somewhat complicated. For example, GPC3 is overexpressed and promotes the growth of hepatocellular carcinoma (HCC) through attenuating FGF and bone morphogenetic protein-7 signaling, whilst stimulating canonical Wnt signaling $(23,24)$. By contrast, GPC3 knockdown in HepG2 HCC cells promotes their growth and GPC3 is frequently silenced in mesotheliomas, ovarian cancer and breast cancer cell lines $(25,26)$. Similar to other glypican members, the overexpression and knockdown of GPC5 expression in rhabdomyosarcoma have been shown to cause increased and decreased cell proliferation, respectively. It was demonstrated that GPC5 increases cell proliferation through potentiating the action of FGF2, hepatocyte growth factor (HGF) and Wnt1A (27). Reduced GPC6 expression has been reported in retinoblastoma. By contrast, GPC6 overexpression was recently associated with the metastatic phenotype of breast cancer (28).

Due to their effects on growth factor secretion and signal regulation, glypicans, as well as other glycan molecules, are generally considered as potential targets for cancer treatment (14). Although the number of studies on the role of glypicans in cancer progression and development is limited, this number is expected to increase in the near future. Since GPC5 and GPC6 expression patterns are currently lacking and have yet to be tackled in gastric cancer, we aimed to analyze, for the first time, the possible roles of these genes in gastric carcinogenesis and cancer progression by determining the GPC5 and GPC6 expression levels in 35 gastric adenocarcinoma samples and corresponding normal mucosa samples.

\section{Patients and methods}

Patients. A total of 35 newly diagnosed patients with primary gastric adenocarcinoma were included in the present study. The tissue samples used were obtained from patients who had undergone surgical tumor resection at the Department of Surgical Oncology, Faculty of Medicine, Ankara University, between October, 2004 and January, 2006, after receiving the patients' informed consent granting permission for anonymous use of their tissue samples in future studies. This study was performed in accordance with the principles of the Declaration of Helsinki and was approved by the Research
Ethics Committee of Ankara University Faculty of Medicine (approval no. 152-4798).

The patients had no family history of cancer and were free of concurrent malignant conditions other than gastric cancer. None of the patients had received chemotherapy or radiotherapy prior to surgery. If the lesions were considered as early gastric cancer during surgical resection, the patients were excluded from the study. Patients who were diagnosed with diffuse type gastric adenocarcinoma during histopathological evaluation were excluded from the study and only patients with the intestinal type of gastric adenocarcinoma were enrolled. Tumoral and normal mucosa samples were obtained from all the subjects. Samples of normal mucosa were collected from areas near the surgical margins and far from the tumors that were macroscopically free of tumor invasion. Only the patients for which RNA samples were available for both tumoral and normal mucosa specimens were included in the present study. Routine histopathological examinations and Helicobacter pylori $(H$. pylori) infection status were performed at the Department of Pathology, Faculty of Medicine, Ankara University, Ankara, Turkey.

RNA isolation and cDNA synthesis. RNA samples were obtained from freshly frozen tissue specimens stored at $-80^{\circ} \mathrm{C}$. RNA extraction was performed using Roche TriPure reagent (cat. no. 11667157001; Roche, Mannheim, Germany) according to the manufacturer's instructions. The extracted RNA was quantified using the Spectramax Plus spectrophotometer and SoftmaxPlus v. 4.8 software (Molecular Devices, Sunnyvale, CA, USA). The synthesis of cDNA from the extracted RNA was performed with the High Fidelity Transcriptor cDNA Synthesis kit (cat. no. 0508995001; Roche), according to the protocol provided by the manufacturer. Briefly, the reaction mixture was prepared by mixing $100 \mathrm{ng}$ of RNA sample, $2 \mu \mathrm{l}$ hexamer primer and $\mathrm{dH}_{2} \mathrm{O}$ to maintain a final volume of $11.4 \mu \mathrm{l}$ and then incubated at $65^{\circ} \mathrm{C}$ for $10 \mathrm{~min}$. After completing the incubation, the reaction mixture was placed on ice and 8.6 $\mu 1$ Master Mix composed of $4 \mu \mathrm{l}$ of $5 \mathrm{X}$ buffer solution $(250 \mathrm{mmol} / \mathrm{l}$ Tris- $\mathrm{HCl}, 150 \mathrm{mmol} / \mathrm{l} \mathrm{KCl}, 40 \mathrm{mmol} / 1 \mathrm{MgCl}_{2}, \mathrm{pH} 8.5$ at $25^{\circ} \mathrm{C}$ ), $0.5 \mu \mathrm{l}$ protector RNase inhibitor $(20 \mathrm{mmol} / \mathrm{HEPES}-\mathrm{KOH}$, $50 \mathrm{mmol} / 1 \mathrm{KCl}, 8 \mathrm{mmol} / \mathrm{l}$ dithiothreitol, $50 \%$ glycerol, $\mathrm{pH} 7.6$ at $\left.4^{\circ} \mathrm{C}\right), 2 \mu \mathrm{l} \mathrm{dNTP}$ mixture ( $10 \mathrm{mmol} / \mathrm{l}$ each), $1 \mu \mathrm{l}$ dithiothreitol $(0.1 \mathrm{M})$ and $1.1 \mu \mathrm{l}$ reverse transcriptase $[200 \mathrm{mmol} / \mathrm{l}$ potassium phosphate, $2 \mathrm{mmol} / 1$ dithiothreitol, $0.2 \%$ Triton X-100 (v/v), $50 \%$ glycerol, $\mathrm{pH}$ 7.2] was added to the reaction mixture. Subsequently, the reaction mixture was incubated at $29^{\circ} \mathrm{C}$ for $10 \mathrm{~min}$, at $48^{\circ} \mathrm{C}$ for $60 \mathrm{~min}$ and at $85^{\circ} \mathrm{C}$ for $5 \mathrm{~min}$. The reactions were performed on a thermocycler (MasterCycler Gradient; Eppendorf, Hamburg, Germany).

Quantitative polymerase chain reaction ( $q P C R)$. GPC5 and GPC6 mRNA expression levels were measured with the qPCR method using LightCycler ${ }^{\circledR} 2.0$ (Roche). The glyceraldehyde 3-phosphate dehydrogenase gene $(G A P D H)$ was used as a housekeeping gene in order to normalize GPC5 and GPC6 expression levels. The intron spanning primers and TaqMan probes used for the expression analysis of each gene were designed using the 'Universal Probe Library Assay Design Center' available at https://www.roche-applied-science.com/sis/rtpcr/upl/index.jsp. The primer and probe sequences are listed on Table I. 
Table I. Primer and probe sequences used for the expression analysis of GPC5, GPC6 and GAPDH genes.

\begin{tabular}{ll}
\hline Genes & \multicolumn{1}{c}{ Sequence $\left(5^{\prime} \rightarrow 3^{\prime}\right)$} \\
\hline $\begin{array}{l}\text { GPC5 } \\
\text { Left primer } \\
\text { Right primer }\end{array}$ & AAGTTCGGAAACTTTTCCAGTG \\
Probe & CGATATGCAAACCTGAAGATCA \\
(FAM ${ }^{\text {TM }}$-labeled) & \\
GPC6 & \\
Left primer & ACCTCGACACAGAGTGGAATC \\
Right primer & GTCCATGACCGACTCAATGTT \\
Probe & TGGCAGAG \\
(FAM ${ }^{\text {TM }}$-labeled) & \\
GAPDH & \\
Left primer & AGCCACATCGCTCAGACAC \\
Right primer & GCCCAATACGACCAAATCC \\
Probe & TGGGGAAG \\
(FAM & \\
\hline
\end{tabular}

$G P C 5$, glypican 5 gene; GPC6, glypican 6 gene; $G A P D H$, glyceraldehyde 3-phosphate dehydrogenase gene; FAM, fluorescein amidite.

For qPCR, the Roche LightCycler ${ }^{\circledR}$ TaqMan ${ }^{\circledR}$ Master kit (cat. no. 04735536001; Roche) was used. The PCR reaction was performed with a final volume of $20 \mu \mathrm{l}$, containing $4 \mu \mathrm{l}$ Master Mix (5X enzyme, FastStartTaq DNA polymerase, reaction buffer, $\mathrm{MgCl}_{2}$ and dNTP), $0.5 \mathrm{mmol} / \mathrm{l}$ of each primer $(2 \mu \mathrm{l}$

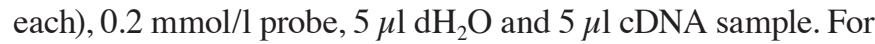
each gene, separate PCR reactions were set up in separate capillaries. The GPC5, GPC6 and GAPDH expression in the tissue of interest was analyzed in the same run. The reaction conditions were as follows: $10 \mathrm{~min}$ at $95^{\circ} \mathrm{C}$ for the pre-incubation step, 45 cycles for $10 \mathrm{sec}$ at $95^{\circ} \mathrm{C}, 30 \mathrm{sec}$ at $50^{\circ} \mathrm{C}$ and $3 \mathrm{sec}$ at $72^{\circ} \mathrm{C}$ for the amplification step and a final cooling step for $30 \mathrm{sec}$ at $40^{\circ} \mathrm{C}$.

Statistical evaluation. Relative gene expression analysis was performed to determine the expression levels of each gene. Gene expression levels were calculated by the $\Delta \Delta \mathrm{Ct}$ method, which is the ratio of the $\mathrm{Ct}$ value for the investigated gene to the $\mathrm{Ct}$ value for the GAPDH (housekeeping) gene in the same tissue. Ct values were obtained using the LightCycler 4.05 software (Roche). Each experiment was run twice and the arithmetic means were used for statistical evaluation.

The difference between gene expression levels in tumor and normal tissues was evaluated with the Wilcoxon signed-ranks test. Associations among gene expression and gender, tumor invasion, lymph node involvement, histological grade and $H$. pylori infection status were assessed by the Mann-Whitney U test. The non-parametric correlations test was used to determine the association between age and gene expression levels. $\mathrm{P}<0.05$ was considered to indicate a statistically significant difference.

\section{Results}

Patient characteristics. The demographic and clinicopathological characteristics of the patients are summarized in Table II.
Table II. Patient demographic and clinical characteristics.

\begin{tabular}{|c|c|}
\hline Characteristics & Percentage \\
\hline \multicolumn{2}{|l|}{ Gender } \\
\hline Male & 66 \\
\hline Female & 34 \\
\hline \multicolumn{2}{|l|}{ Age (years) } \\
\hline$>50$ & 27 \\
\hline$<50$ & 73 \\
\hline \multicolumn{2}{|c|}{ TNM classification } \\
\hline \multicolumn{2}{|l|}{ Tumor invasion } \\
\hline $\mathrm{T} 1$ & 6 \\
\hline $\mathrm{T} 2$ & 12 \\
\hline $\mathrm{T} 3$ & 79 \\
\hline $\mathrm{T} 4$ & 3 \\
\hline \multicolumn{2}{|c|}{ Lymph node involvement } \\
\hline N0 & 32 \\
\hline N1 & 27 \\
\hline $\mathrm{N} 2$ & 29 \\
\hline N3 & 12 \\
\hline \multicolumn{2}{|c|}{ Distant metastasis } \\
\hline M0 & 97 \\
\hline M1 & 3 \\
\hline \multicolumn{2}{|c|}{ Histological grade } \\
\hline G1 & 49 \\
\hline $\mathrm{G} 2$ & 14 \\
\hline G3 & 37 \\
\hline \multicolumn{2}{|c|}{ Helicobacter pylori infection } \\
\hline+ & 43 \\
\hline- & 57 \\
\hline \multicolumn{2}{|l|}{ Tumor size (cm) } \\
\hline 2 & 16 \\
\hline $2-5$ & 42 \\
\hline 5 & 42 \\
\hline \multicolumn{2}{|l|}{ Resection type } \\
\hline Distal & 50 \\
\hline Proximal & 3 \\
\hline Total & 47 \\
\hline
\end{tabular}

Of the patients, 23 were men and 12 were women, with a mean age of $59.45 \pm 10.89$ and $60.55 \pm 14.73$ years, respectively. The average body mass index was calculated as $26.3,82 \%$ of the patients were diagnosed at late stages (T3 and T4) and 68\% of the patients had lymph node metastasis. Only 1 patient had a distant metastasis. Well-differentiated tumors were detected in $49 \%$ of the patients, whereas $51 \%$ of the patients had poorly differentiated tumors. H. pylori infection was positive in $43 \%$ of our patients.

GPC5 and GPC6 expression. None of the gastric adenocarcinoma patients exhibited detectable GPC5 expression in either the normal or the tumor samples. Therefore, any statistical evaluation was not performed regarding GPC5 expression in gastric cancer. However, all the patients exhibited appreciable 
A

A Target amplification curves

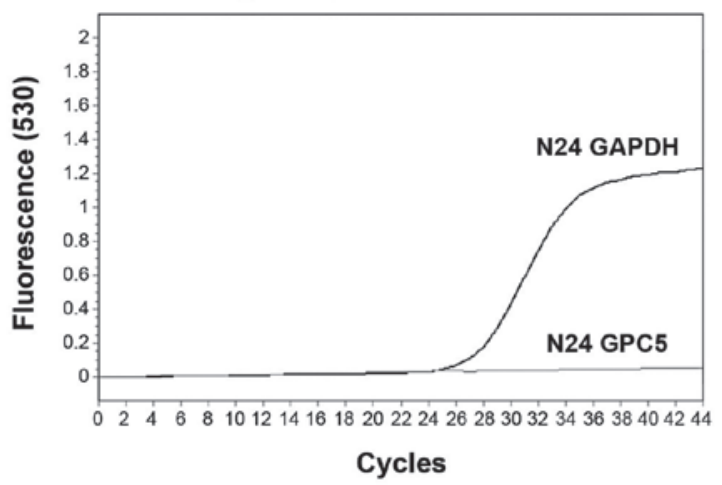

C

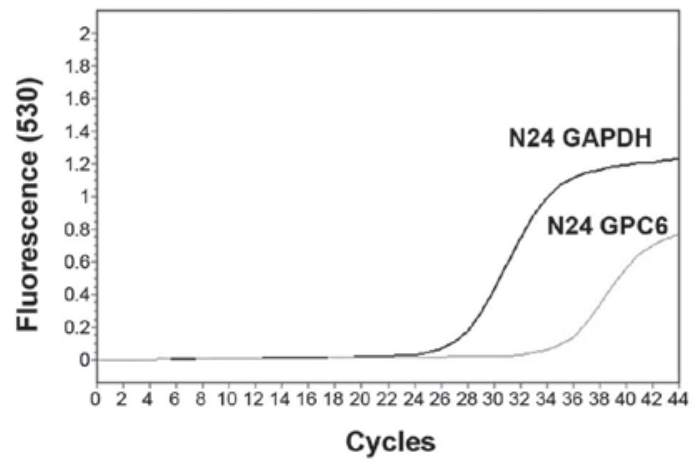

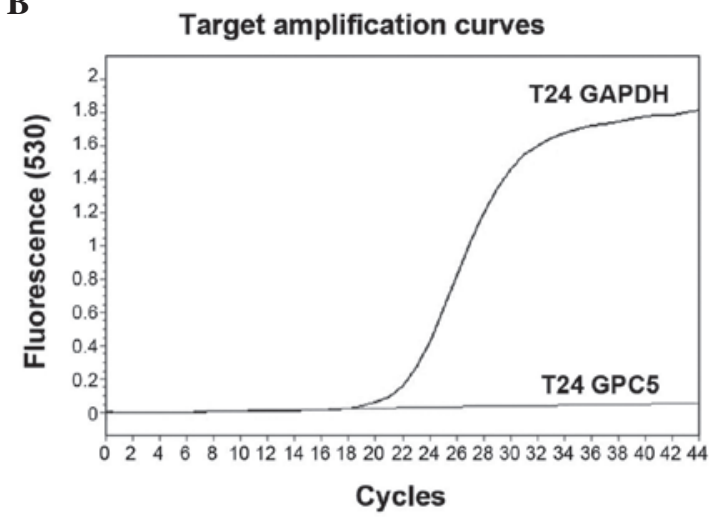

D

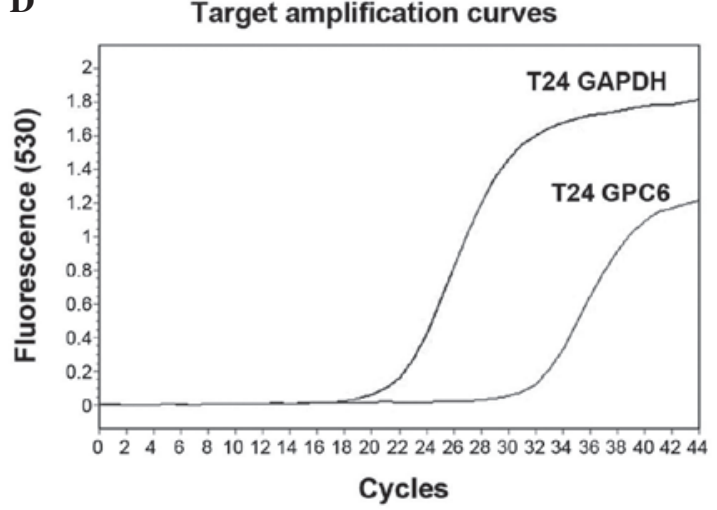

Figure 1. Glypican 5 (GPC5) and glyceraldehyde 3-phosphate dehydrogenase (GAPDH) gene amplification curves obtained from (A) normal and (B) tumor samples from patient no. 24; and glypican 6 (GPC6) and GAPDH gene amplification curves from (C) normal and (D) tumor samples from the same patient.

GPC6 expression, which was detected in the tumor tissues as well as in the normal gastric mucosa samples. Representative GPC5, GPC6 and GAPDH amplification curves obtained from normal and tumor samples belonging to the same patient are depicted in Fig. 1. The extent of GPC6 expression varied between 1.21 and 1.37, with a median value of 1.28 in normal gastric mucosa samples. By contrast, in tumor samples GPC6 expression ranged between 0.69 and 1.46 , with a median value of 1.31. The mean value \pm standard deviation (SD) of GPC6 expression was calculated as $1.28 \pm 0.04$ and $1.30 \pm 0.12$ in normal and tumor tissues, respectively. The difference between the mean GPC6 expression levels in normal and tumor tissues were found to be statistically significant $(\mathrm{P}=0.039)$. GPC6 expression levels were not found to be significantly associated with age or gender.

Associations between GPC6 expression and clinicopathological parameters. The associations between GPC6 expression and clinicopathological parameters, including TNM classification, histopathological grade and $H$. pylori infection status are tabulated in Table III. The GPC6 $\sigma_{\text {tumor }} / G P C 6_{\text {normal }}$ ratio for each patient was calculated prior to any statistical evaluations, in order to exclude GPC6 expression of the background mucosa. The mean GPC6 expression level \pm SD of early-stage (T1 and T2) and late-stage (T3 and T4) tumor samples was $1.01 \pm 0.07$ and $1.01 \pm 0.10$, respectively, with no statistically significant difference $(\mathrm{P}>0.05)$. Similarly, when the expression levels in lymph node metastasis-negative samples (N0) were compared to those in lymph node metastasis-positive samples
(N1, N2 and N3) (1.04 \pm 0.74 vs. 0.99 \pm 0.10$)$, no significant difference was detected $(\mathrm{P}>0.05)$. As distant metastasis was observed in only 1 patient, the GPC6 expression levels in M0 and M1 tumors were not subjected to statistical analysis.

Well-differentiated (G1) gastric cancer tissues exhibited a mean \pm SD GPC6 expression level of $1.02 \pm 0.53$ and, similarly, poorly differentiated (G2 and G3) tumor samples had a mean value of $1.01 \pm 0.13(\mathrm{P}>0.05)$. The GPC6 expression levels of $H$. pylori-positive and -negative samples were $1.01 \pm 0.46$ and $1.01 \pm 0.15$, respectively, with no statistically significant differences $(\mathrm{P}>0.05)$.

\section{Discussion}

Gastric cancer remains a significant health problem and is second only to lung cancer as a leading cause of cancer-related mortality worldwide (29). Its high incidence is considered to be the result of environmental as well as genetic factors. A number of studies have clearly demonstrated that multiple genetic alterations are responsible for the development and progression of gastric cancer (30-35). Over the last few years, several attempts have been made to better define the genetic profile of gastric tumors, with the aim to improve the effectiveness of early diagnosis and/or prognostic stratification. In our recent study, we documented the changes of DNA copy number in 43 patients with gastric adenocarcinomas by using HR-CGH in Turkey to identify the types of genomic imbalances in association with development and progression of gastric cancer (6). In that study, we reported that the gains of 
Table III. Statistical evaluation of clinicopathological parameters.

\begin{tabular}{lcc}
\hline & \multicolumn{2}{c}{$G P C \sigma_{\text {tumor }} / G P C \sigma_{\text {normal }}$} \\
\cline { 2 - 3 } $\begin{array}{l}\text { Clinicopathological } \\
\text { parameters }\end{array}$ & $\begin{array}{c}\text { Median } \\
(\text { min-max })\end{array}$ \\
\hline
\end{tabular}

\begin{tabular}{|c|c|c|}
\hline TNM stage ${ }^{a}$ & & \\
\hline Tumor invasion & & \\
\hline $\mathrm{T} 1 / \mathrm{T} 2(\mathrm{n}=6)$ & $1.01 \pm 0.07$ & $1.02(0.90-1.10)$ \\
\hline T3/T4 (n=28) & $1.01 \pm 0.10$ & $1.02(0.55-1.18)$ \\
\hline & & 0.912 \\
\hline
\end{tabular}

Lymph node involvement ${ }^{\mathrm{b}}$

\begin{tabular}{llr}
$\mathrm{N} 0(\mathrm{n}=11)$ & $1.04 \pm 0.74$ & $1.04(0.90-1.18)$ \\
$\mathrm{N} 1 / \mathrm{N} 2 / \mathrm{N} 3(\mathrm{n}=23)$ & $0.99 \pm 0.10$ & $1.00(0.55-1.10)$ \\
& \multicolumn{3}{c}{$\mathrm{P}=0.08$}
\end{tabular}

Distant metastasis ${ }^{\mathrm{b}}$

$\begin{array}{lcc}\text { M0 }(\mathrm{n}=33) & 1.01 \pm 0.09 & 1.02(0.55-1.18) \\ \mathrm{M} 1(\mathrm{n}=1) & \mathrm{NC} & \\ & & \mathrm{P}=\mathrm{NC}\end{array}$

H. pylori infection ${ }^{\mathrm{b}}$

$\begin{array}{llr}\text { Positive }(\mathrm{n}=17) & 1.01 \pm 0.46 & 1.01(0.90-1.10) \\ \text { Negative }(\mathrm{n}=13) & 1.01 \pm 0.15 & 1.05(0.55-1.18) \\ & \mathrm{P}=0.127\end{array}$

Histological grade ${ }^{b}$

$\begin{array}{lcc}\mathrm{G} 1(\mathrm{n}=17) & 1.02 \pm 0.53 & 1.02(0.90-1.10) \\ \mathrm{G} 2 / \mathrm{G} 3(\mathrm{n}=18) & 1.01 \pm 0.13 & 1.03(0.55-1.18) \\ & \mathrm{P}=0.644\end{array}$

${ }^{\text {aTNM }}$ classification data were available for $34 / 35$ patients. ' Mann-Whitney U test. GPC6, glypican 6 gene; SD, standard deviation; $\mathrm{NC}$, not calculated due to the large numerical discrepancy in sample sizes of M0/M1 tumors and intestinal/diffuse type tumors; H. pylori, Helicobacter pylori.

13q with a MOR 13q21-q32 provided evidence suggesting a correlation with an increased incidence of lymph node metastasis (6). To the best of our knowledge, the present study is the first to analyze the expression levels of the GPC5 and GPC6 genes, located at $13 \mathrm{q} 21$ region, as possible targets for genomic amplification events in gastric cancer.

HSPGs, including GPC5 and GPC6, are mostly found on the surfaces of adhered cells and in the extracellular matrix that surrounds and supports them. Due to their negatively charged heparin-like moieties, HSPG molecules bind and regulate several matrix components, growth factors, proteinase inhibitors and cell-cell and cell-matrix adhesion molecules (36). Cell surface-bound HSPGs are known to function as co-receptors for a number of growth factors, such as FGF, EGF, Wnt and the transforming growth factor $\beta$ (TGF- $\beta$ ) superfamily, which play important roles during embryonic development and tumorigenesis. Acting as co-receptors, these molecules facilitate the interaction between specific signaling receptors and their ligands, thereby regulating the function of the associated signaling pathways $(12,13,37-39)$. Since glypicans regulate the activity of growth and survival factors, changes in their expression may be associated with tumor progression. Therefore, HSPGs are considered to play an important role in carcinogenesis. In support of this hypothesis, it was demonstrated that GPCl is overexpressed in pancreatic cancer (22). Similarly, GPC3 expression has been reported to be increased in $\mathrm{HCC}$ (15).

Several studies investigating the role of GPC5 and GPC6 in different types of cancer have been published. Yu et al (40) reported that GPC5 is overexpressed in different lymphoma cell lines and they suggested that this gene is a likely target for 13q31-q32 amplification in lymphomas and other tumors. Conversely, a study on lung cancer demonstrated that GPC5 expression, as a result of a genetic variation, is significantly lower in adenocarcinoma compared to that in normal lung tissue (41). Another report by the same authors suggested that GPC5 regulates lung cancer development through a complex pathway network, although there is no direct evidence (20).

A study on rhabdomyosarcoma tissues has also reported a genomic amplification of the 13q31-q32 region. The results of that study demonstrated a higher GPC 5 expression in tumoral compared to that in normal skeletal muscle tissues; this overexpression triggered cell proliferation by modifying the cell surface distribution of FGF2, HGF and Wnt1A receptors (27). A recent publication indicated that GPC5 regulates rhabdomyosarcoma cell proliferation by activating the Hedgehog (Hh) signaling pathway. It has been suggested that this function was mediated by facilitating/stabilizing the interaction between $\mathrm{Hh}$ and Patched 1 (42).

Saunders et al (11) investigated the expression levels of GPC5 in different embryonic and adult tissues. The authors of that study demonstrated that GPC5 is expressed in almost all embryonic tissues and this expression is maintained and even increased in adult brains, whereas in all other adult tissues, including the gastric epithelium, this expression is markedly suppressed to trace levels. This result suggests that GPC5 expression may play an important role in the regulation of growth and differentiation during mammalian development. In accordance with the previous studies, our study revealed that none of the normal gastric tissues expressed GPC5. It is known that alterations in the expression levels of the genes that are expressed during embryonic development but suppressed in adult tissues are associated with a number of dysmorphic conditions and cancers. Of note, unlike other cancer types, GPC5 expression was not detected in our gastric cancer tissue samples. Since GPC5 gene remains silent in gastric cancer tissues, our results suggest that this gene has no potential role in gastric carcinogenesis. In addition, our study demonstrated that the increase in genomic copy numbers may not always lead to the overexpression of the genes located at the amplification region. Other mechanisms participating in the regulation of gene expression, such as epigenetic regulation, may explain this finding.

The number of studies investigating the role of GPC6 gene in cancer is limited. A recent study reported that a subset of genes, including GPC6, was found to be recurrently altered in 23 prostate cancer tissues obtained from 16 different fatal metastatic tumors and 3 high-grade primary carcinomas, using whole-genome sequencing (43). Lau et al (44) investigated sporadic retinoblastoma cases using 140 microsatellite 
markers and detected a decrease in GPC6 expression due to loss of heterozygosity of the related locus. In that study, non-random allelic loss at the $13 \mathrm{q}$ region and the decrease in the GPC6 mRNA levels were reported to be associated with retinoblastoma development. By contrast, overexpression of the GPC6 gene was found to lead to increased cell migration via reorganization of the cell skeleton in the 143B osteosarcoma cell line. In accordance with this observation, it was demonstrated that GPC6 suppression leads to a slowing of cell migration in the MCF10A cell line (45). In breast cancer cell lines, Yiu et al (28) demonstrated that GPC6 is a target gene of nuclear factor of activated $\mathrm{T}$ cells (NFAT), which promotes breast cancer invasion. Increased GPC6 expression through endogenous NFAT activation facilitates invasive migration of cancer cells in a manner that requires Wnt5A signaling. GPC6 induction of Wnt5A activates JNK and p38 MAPK pathways.

Our study demonstrated that GPC6 was expressed in normal mucosa as well as tumor samples obtained from gastric cancer patients, with the levels in tumor samples being significantly higher. However, the GPC6 expression levels in the tumor samples were not found to be significantly associated with the clinicopathological parameters investigated. All these findings suggest that this gene plays an important role in early gastric carcinogenesis, but not in disease prognosis. Since the sample size of the present study was relatively small, further studies with a larger sample size are required to assess the association between GPC6 expression and the prognosis of gastric cancer more accurately. We suggest that GPC6 expression may induce gastric carcinogenesis through facilitating the aforementioned signaling pathways, including Wnt, Hh, FGF, EGF, growth hormone factor and TGF- $\beta$ pathways. Our results also indicate that, after determining a reliable cut-off point and evaluating the sensitivity and specificity for the GPC6 mRNA expression level, it may be used as a candidate biomarker for the diagnosis of gastric cancer. To achieve these goals, GPC6 mRNA expression levels must also be quantified in normal gastric samples from healthy individuals.

In conclusion, studies increasingly support the fact that glypicans are able to modify and regulate cell adhesion, migration and extracellular matrix organization and decrease the growth factor concentration required by the cells, by facilitating the formation of ligand-receptor complexes. All these functions are considered to be important mechanisms in tumorigenesis. Our results suggest that GPC6, but not GPC5, appear to be a possible target gene for the amplification of $13 q 21-q 32$ in gastric adenocarcinoma. Further in vitro cell culture experiments and in vivo animal studies are required to fully elucidate the possible molecular mechanisms of GPC6-mediated gastric carcinogenesis.

\section{Acknowledgements}

This study was supported by grants from The Scientific and Technological Research Council of Turkey (grant no. 109S250) and approved by the Research Ethics Committee of Ankara University Faculty of Medicine (approval no. 152-4798). Routine histopathological examinations and $H$. pylori infection status assessment were performed at the Department of Pathology, Faculty of Medicine, Ankara University, Ankara, Turkey.

\section{References}

1. GLOBOCAN: Cancer Incidence and Mortality Worldwide in 2008. http://globocan.iarc.fr. Accessed February ??, 2009.

2. Stock M and Otto F: Gene deregulation in gastric cancer. Gene 360: 1-19, 2005.

3. Zheng L, Wang L, Ajani J and Xie E: Molecular basis of gastric cancer development and progression. Gastric Cancer 7: 61-77, 2004.

4. Futreal PA, Coin L, Marshall M, Down T, Hubbard T, Wooster R, Rahman N and Stratton MR: A census of human cancer genes. Nat Rev Cancer 4: 177-183, 2004.

5. Scartozzi M, Galizia E, Freddari F, Berardi R, Cellerino R and Cascinu S: Molecular biology of sporadic gastric cancer: prognostic indicators and novel therapeutic approaches. Cancer Treat Rev 30: 451-459, 2004.

6. Gumus-Akay G, Unal AE, Elhan AH, Bayar S, Karadayt K, Sunguroglu A, Kadikiran A and Tukun A: DNA copy number changes in gastric adenocarcinomas: high resolution-comparative genomic hybridization study in Turkey. Arch Med Res 40: 551-560, 2009

7. Syrokou A, Tzanakakis G, Tsegenidis T, Hjerpe A and Karamanos NK: Effects of glycosaminoglycans on proliferation of epithelial and fibroblast human malignant mesothelioma cells: a structure-function relationship. Cell Prolif 32: 85-99, 1999.

8. Kirn-Safran C, Farach-Carson MC and Carson DD: Multifunctionality of extracellular and cell surface heparan sulfate proteoglycans. Cell Mol Life Sci 66: 3421-3434, 2009

9. Jackson RL, Busch SJ and Cardin AD: Glycosaminoglycans: molecular properties, protein interactions and role in physiological processes. Physiol Rev 71: 481-539, 1991.

10. De Cat B and David G: Developmental roles of the glypicans. Semin Cell Dev Biol 12: 117-125, 2001.

11. Saunders S, Paine-Saunders S and Lander AD: Expression of the cell surface proteoglycan glypican-5 is developmentally regulated in kidney, limb, and brain. Dev Biol 190: 78-93, 1997.

12. Yayon A, Klagsbrun M, Esko JD, Leder P and Ornitz DM: Cell surface, heparin-like molecules are required for binding of basic fibroblast growth factor to its high affinity receptor. Cell 64: 841-848, 1991.

13. Cumberledge S and Reichsman F: Glycosaminoglycans and WNTs: just a spoonful of sugar helps the signal go down. Trends Genet 13: 421-423, 1997.

14. Fuster MM and Esko JD: The sweet and sour of cancer: glycans as novel therapeutic targets. Nat Rev Cancer 5: 526-542, 2005.

15. Hsu HC, Cheng W and Lai PL: Cloning and expression of a developmentally regulated transcript MXR7 in hepatocellular carcinoma: biological significance and temporospatial distribution. Cancer Res 57: 5179-5184, 1997.

16. Ning S, Bin C, Na H, et al: Glypican-3, a novel prognostic marker of hepatocellular cancer, is related with postoperative metastasis and recurrence in hepatocellular cancer patients. Mol Biol Rep 39: 351-357, 2012.

17. Ozkan H, Erdal H, Kocak E, Tutkak H, Karaeren Z, Yakut M and Koklu S: Diagnostic and prognostic role of serum glypican 3 in patients with hepatocellular carcinoma. J Clin Lab Anal 25: 350-353, 2011.

18. Zhang L, Liu H, Sun L, Li N, Ding H and Zheng J: Glypican-3 as a potential differential diagnosis marker for hepatocellular carcinoma: a tissue microarray-based study. Acta Histochem 114: 547-552, 2012.

19. Liu S, Li Y, Chen W, Zheng P, Liu T, He W, Zhang J and Zeng X: Silencing glypican-3 expression induces apoptosis in human hepatocellular carcinoma cells. Biochem Biophys Res Commun 419: 656-661, 2012.

20. Li Y and Yang P: GPC5 gene and its related pathways in lung cancer. J Thorac Oncol 6: 2-5, 2011.

21. Su G, Meyer K, Nandini CD, Qiao D, Salamat S and Friedl A: Glypican-1 is frequently overexpressed in human gliomas and enhances FGF-2 signaling in glioma cells. Am J Pathol 168: 2014-2026, 2006.

22. Kleeff J, Ishiwata T, Kumbasar A, Friess H, Buchler MW, Lander AD and Korc M: The cell-surface heparan sulfate proteoglycan glypican-1 regulates growth factor action in pancreatic carcinoma cells and is overexpressed in human pancreatic cancer. J Clin Invest 102: 1662-1673, 1998.

23. Midorikawa $Y$, Ishikawa $S$, Iwanari $H$, Imamura T, Sakamoto $H$, Miyazono K, Kodama T, Makuuchi $M$ and Aburatani H: Glypican-3, overexpressed in hepatocellular carcinoma, modulates FGF2 and BMP-7 signaling. Int J Cancer 103: $455-465,2003$ 
24. Capurro MI, Xiang YY, Lobe C and Filmus J: Glypican-3 promotes the growth of hepatocellular carcinoma by stimulating canonical Wnt signaling. Cancer Res 65: 6245-6254, 2005.

25. Filmus J and Selleck SB: Glypicans: proteoglycans with a surprise. J Clin Invest 108: 497-501, 2001.

26. Sung YK, Hwang SY, Farooq M, Kim JC and Kim MK: Growth promotion of HepG2 hepatoma cells by antisense-mediated knockdown of glypican-3 is independent of insulin-like growth factor 2 signaling. Exp Mol Med 35: 257-262, 2003.

27. Williamson D, Selfe J, Gordon T, Lu YJ, Pritchard-Jones K, Murai K, Jones P, Workman P and Shipley J: Role for amplification and expression of glypican-5 in rhabdomyosarcoma. Cancer Res 67: 57-65, 2007.

28. Yiu GK, Kaunisto A, Chin YR and Toker A: NFAT promotes carcinoma invasive migration through glypican-6. Biochem J 440: 157-166, 2011.

29. WHO Cancer Fact sheet $\mathrm{N}^{\circ} 297$, World Health Organization. http://www.who.int/mediacentre/factsheets/fs297/en/. Accessed February, 2009.

30. Garziera M, De Re V, Geremia S, et al: A novel CDH1 germline missense mutation in a sporadic gastric cancer patient in north-east of Italy. Clin Exp Med 13: 149-157, 2013.

31. Kang JM, Lee BM, Kim N, Lee HS, Lee HE, Park JH, Kim JS, Jung HC and Song IS: CDX1 and CDX2 expression in intestinal metaplasia, dysplasia and gastric cancer. J Korean Med Sci 26 : 647-653, 2011.

32. Tsapralis D, Panayiotides I, Peros G, Liakakos T and Karamitopoulou E: Human epidermal growth factor receptor-2 gene amplification in gastric cancer using tissue microarray technology. World J Gastroenterol 18: 150-155, 2012.

33. Furuta K, Arao T, Sakai K, et al: Integrated analysis of whole genome exon array and array-comparative genomic hybridization in gastric and colorectal cancer cells. Cancer Sci 103 : 221-227, 2012

34. Leal MF, Calcagno DQ, Borges da Costa Jde F, Silva TC, Khayat AS, Chen ES, Assumpcao PP, de Arruda Cardoso Smith M and Burbano RR: MYC, TP53, and chromosome 17 copy-number alterations in multiple gastric cancer cell lines and in their parental primary tumors. J Biomed Biotechnol 2011: 631268, 2011.
35. Ye YW, Wu JH, Wang CM, Zhou Y, Du CY, Zheng BQ, Cao X, Zhou XY, Sun MH and Shi YQ: Sox 17 regulates proliferation and cell cycle during gastric cancer progression. Cancer Lett 307: 124-131, 2011.

36. Hileman RE, Fromm JR, Weiler JM and Linhardt RJ: Glycosaminoglycan-protein interactions: definition of consensus sites in glycosaminoglycan binding proteins. Bioessays 20: 156-167, 1998.

37. Higashiyama S, Abraham JA and Klagsbrun M: Heparin-binding EGF-like growth factor stimulation of smooth muscle cell migration: dependence on interactions with cell surface heparan sulfate. J Cell Biol 122: 933-940, 1993.

38. Jackson SM, Nakato H, Sugiura M, Jannuzi A, Oakes R, Kaluza V, Golden C and Selleck SB: Dally, a Drosophila glypican, controls cellular responses to the TGF-beta-related morphogen, Dpp. Development 124: 4113-4120, 1997.

39. Godin RE, Takaesu NT, Robertson EJ and Dudley AT: Regulation of BMP7 expression during kidney development. Development 125: 3473-3482, 1998.

40. Yu W, Inoue J, Imoto I, Matsuo Y, Karpas A and Inazawa J: GPC5 is a possible target for the 13q31-q32 amplification detected in lymphoma cell lines. J Hum Genet 48: 331-335, 2003.

41. Li Y, Sheu CC, Ye Y, et al: Genetic variants and risk of lung cancer in never smokers: a genome-wide association study. Lancet Oncol 11: 321-330, 2010.

42. Li F, Shi W, Capurro M and Filmus J: Glypican-5 stimulates rhabdomyosarcoma cell proliferation by activating Hedgehog signaling. J Cell Biol 192: 691-704, 2011.

43. Kumar A, White TA, MacKenzie AP, et al: Exome sequencing identifies a spectrum of mutation frequencies in advanced and lethal prostate cancers. Proc Natl Acad Sci USA 108: 17087-17092, 2011.

44. Lau CS, Yu CB, Wong HK, et al: Allelic imbalance at $13 \mathrm{q} 31$ is associated with reduced GPC6 in Chinese with sporadic retinoblastoma. Br J Ophthalmol 94: 357-362, 2010.

45. Lacrima K: Role of glypican-6 and NG2 as metastasis promoting factors. Universita' Degli Studi Di Parma, Dottorato di ricerca in Fisiopatologia Sistemica, 2005. 